\title{
CAN SLEEP DURATION HELP EXPLAIN DIFFERENCES IN THE HAP- PINESS INDEX ACROSS NATIONS?
}

\author{
Azza Mohamed Kamal ${ }^{1}$
}

date of paper receipt:

date of sending to review:

02.09.2019.

date of review receipt:

29.08.2019.

Original Article

doi: 10.2478/eoik-2019-0014

09.09.2019.

UDK: 334.72.02:159.9.019.4(100)

${ }^{1}$ MSA University, Egypt

\begin{abstract}
Inadequate sleep is an important public health problem that can affect one in every three adults; however, it received little attention in the economics of happiness research. The objective of this article is to examine whether sleep adequacy contributes to the explanation of variation in happiness index levels across countries. Analysis was undertaken using ordinary least squares regression method. The dependent variable is the self-reported happiness index developed by the Gallup poll and published in the World Happiness Report. Two alternative model specifications were used. The first included average sleep minutes per country, GDP per capita(purchasing power parity), unemployment rate, and environmental performance index. The second model specification included average sleep minutes per country, GDP (purchasing power parity), and economic freedom index. Both model specifications met several robustness checks, and showed overall significance and significant coefficients. Results showed that an increase in average sleep duration by 10 minutes is associated with an improvement in the happiness score by 0.1 and 0.15 points in the first and second model specifications respectively, noting an average happiness score of 6.2 in the country sample. The conclusion that sleep duration contributes to explaining variation in happiness levels across countries is a call for policy makers to consider policies targeting improvement in sleep adequacy as priority, and to direct more resources to further research in the area of sleep economics. Previous studies in the area of happiness economics did not consider sleep in explaining differences in happiness among countries, and previous studies in the area of economics of sleep did not consider the happiness index at a global level.
\end{abstract}

Keywords:

Happiness Economics, Happiness Index, Sleep Economics, Sleep Deprivation, Inadequate Sleep

JEL: 118, 131 


\section{INTRODUCTION}

Inadequate sleep is an important public health problem that can affect one in every three adults [1]. Some cases of inadequate sleep could relate to clinical sleep disorders, but many cases could relate to work, school, and life-style related factors [1] including a lack of physical activity, school start time, unrealistic time pressures at work, working irregular hours and long commuting times and digital media use [2]. Insufficient sleep is related to higher mortality risks, as an individual that sleeps on average less than six hours per night, has a $13 \%$ higher mortality risk than an individual who sleeps between 7 and 9 hours-the recommended healthy sleep duration [2]. The annual costs of inadequate sleep as a percentage of GDP are estimated to reach 3.3\%, 2.6\%, 1.8\%, 1.6\%, and 1.5\%, by the year 2030, in Japan, United States, United Kingdom, Germany and Canada respectively [2]; such cost estimates relate to mortality and work productivity effects of inadequate sleep.

Sleep has received little attention in happiness research, whether from the medical or the economic point of view [3,4]. While the link between sleep and life satisfaction could be bi-directional, there is evidence that good sleep might affect how positively a person evaluates their life [3]. Baglioni et.al. (2011) meta-analysis of 21 studies found that the non-depressed people with insomnia have double the risk of developing depression compared to others without sleep difficulties [5]. Therefore, that study recommended a general preventive strategy based on early treatment programs for insomnia in order to reduce the risk for developing depression in the general population. Dinges et. al. (1997) experiment found that individuals who slept only 4.5 hours per night for one week recorded fatigue, confusion, tension, emotional complaints and total mood disturbance during the study [6]. It took them two full days to recover after resuming normal sleep, and they reported significant improvement in mood. Piper uses the German Socio Economic Panel (SOEP) which has, since 2008 , included questions about the amount of sleep a respondent has, along with questions about how satisfied a person is with their life, and several demographic and socio-economic questions[4]. The study found that sleep is an important factor for life satisfaction and that maximum life satisfaction is associated with about eight hours of sleep on a typical weekday. However, the average sleep duration of Germans included in the study was 7 hours, so more sleep would lead to a higher reported satisfaction with life.

Several studies attempted to explain the differences between happiness levels (or self-reported subjective well-being) across countries. A large strand of the happiness literature focused on the question of whether richer nations are happier. The "Easterlin Happiness-Income Paradox" arising from Easterlin (1974) was sometimes misinterpreted in the literature as indicating no relation between happiness and economic development [7]. However, the Easterlin paradox states that "at a point in time both among and within nations, happiness varies directly with income, but over time, happiness does not increase when a country's income increases. We are talking here about the time series relationship of happiness and income in the long term, usually at least 10 years, sometimes more" [8]. Several studies published after 1974 tried to criticize and disproof Easterlin (1974) based on misinterpretation [8]. For example, Stevenson and Wolfers (2008) found that income and economic growth contribute to explaining the differences in subjective well-being across nations; however, their analysis was for short term effects[9], which does not contradict the Paradox [8]. The results of Deaton (2008) [10] confirming the relationship between happiness and income were widely used in the economic and non-economic literature as a disproof of the Happiness-Income paradox, but it relied on cross-sectional data at a one point in time, which again does not disproof the paradox as the later only applies to the long-term relationship [8].

Gropper, Lawson, and Thorne( 2012) used per capita GDP and the economic freedom index to explain differences in happiness levels across countries, and both variables contributed significantly to explaining the variation in happiness[11]. The World Happiness Report of 2019 used per capita GDP, perception of corruption, social support, healthy life expectancy at birth, generosity, and freedom to make life choices to explain variation in happiness levels across countries [12]. Gorham, 
Lehman, and Kelly (2019) examined the relationship between the Environmental performance index and six variables, where the relationship with each variable is examined separately[13]. The study found a linear relationship between the environmental index and the happiness index, but the study suggested correlation rather than causality. Majeed and Mumtaz (2017) used the environmental degradation indicators of the Environmental Performance Index (EPI) along with income to explain the variability of happiness levels across nations[14].

However, to the knowledge of the author, no previous study examined whether there is a linkage between sleep duration and the happiness index differences across nations. Therefore, the current study aims at examining whether sleep duration contributes to the explanation of variation in happiness index levels across countries. The results will be useful for drawing the attention of policy makers towards the importance of polices that address the problem of sleep inadequacy, and along with evidence from previous research that estimates the economic cost of inadequate sleep, could provide a justification for expenditures directed to such policies and to further research in the area of sleep and happiness.

\section{DATA AND METHODOLOGY}

In order to estimate the relationship between average sleep duration and the overall happiness in a country, the Ordinary Least Squares Multiple Regression Model is employed. The dependent variable is the happiness index from the World Happiness Report of 2019 [12]. For the independent variables, two alternative model specifications were tested. The first included average sleep minutes per country, GDP (purchasing power parity), unemployment, and environmental performance index. The second model specification included average sleep minutes per country, GDP (purchasing power parity), and economic freedom index.

\subsection{FIRST MODEL SPECIFICATION}

The first model specification is as follows:

$$
\text { Happiness }_{\mathrm{j}}=b_{0}+b_{1} \text { Sleep }_{\mathrm{j}}+b_{2} \mathrm{GDP}_{\mathrm{j}}+b_{3} \text { Economicfreedom }_{\mathrm{j}}
$$

where represents the happiness index, represents the average daily sleep minutes of country $j$, represents per capita GDP in purchasing power parity terms, Unemploymentj refers to unemployment rate, and Environment refers to the Environmental quality index of each country. The dependent variable Happinessj is the Happiness Index from World Happiness Report of 2019. The index depends on responses to a Cantril ladder question, using a survey collected by Gallup of 430,000 respondents from 103 countries, who were asked to value their lives today on a 0 to 10 scale, with the worst possible life as a 0 and the best possible life as a 10 . This index is selected because it measures happiness based on people's perception directly (self-reported) rather than being inferred from a model, and because recent data is available. Another potential measurement of self-reported happiness is the World Value Survey report which requests respondents to answer a question: "Taking all things together, would you say you are (i) Very happy, (ii) Rather happy, (iii) Not very happy or (iv) Not at all happy". It comprises a long time series, but the most recent published database is for 2014 .

The independent variables are: average sleep hours per day by country, GDP per capita (Purchasing power parity), unemployment rate, and environment quality index. Data about average sleep hours by country is available for 55 countries from Asia, Europe, North America, Latin America, Middle East and North Africa, and South Africa ( Figure A.1 in the appendix shows the countries included in the sample). The data is obtained from Troser(2019) [15] based on data from Sleep Cycle. Sleep Cycle is a sleep tracking app which collects data from its users [16]. Therefore, the data could be 
characterized by selection bias. However, this is, currently, the most comprehensive cross-country dataset available about average sleep hours. GDP purchasing power parity data and unemployment rate data of 2017 are extracted from the World Development Indicators Database [17]. Environment quality is measured by the 2018 environmental performance index developed by the Yale's Center for Environmental Law and Policy and other collaborators [18]. It is a composite index of several indicators of ecosystem vitality and environmental health like water quality, carbon emissions, and tree cover loss.

There are several other independent variables that could be suggested. However, many of the potential variables would have high collinearity with the other independent variables. For example, the rule of law index (World Justice Project, 2018) was added to the above equation but estimating the correlation matrix of coefficients showed high correlation with each of GDP per capita and sleep hours[19]. The same applies to the corruption perceptions index published by Transparency International [20]. Therefore, those variables were excluded from the model. Also, the omitted variable test did not show that there is a specification error with equation 1 . It should be noted that the 2019 World Happiness Report tested a regression model of the happiness index on several independent variables including corruption [12]. However, the corruption variable is defined differently, because it is based on the respondents' view of corruption, rather than the global index. Lang (2012) tested a regression of the Gallup happiness index on the corruption index of transparency, among other variables, but the coefficient of this variable was not significant, which could indicate correlation with other variables in her model like unemployment or human development index [21].

\subsection{SECOND MODEL SPECIFICATION}

This specification builds on the model of Gropper, Lawson, and Thorne (2012) which included the economic freedom index and per capita GDP as determinants of happiness [11]. Using several definitions of happiness, and alternative model specifications like interaction variable between GDP and the economic freedom index, the model proved to be significant. Therefore, the second model specification adds the number of sleep hours as a third independent variable to Gropper, Lawson, and Thorne (2012) model specification [11] to explain happiness.

$$
\text { Happiness }_{\mathrm{j}}=b_{0}+b_{1} \text { Sleep }_{\mathrm{j}}+b_{2} \mathrm{GDP}_{\mathrm{j}}+b_{3} \text { Economicfreedom }_{\mathrm{j}}+b_{4}\left(\mathrm{GDP}_{\mathrm{j}} \quad \text { Economicfreedom }_{\mathrm{j}}\right)
$$

where represents the happiness index in country $j$, represents the average daily sleep minutes of country $j$, Economicfreedom $j$ represents the economic freedom index.

The index of economic freedom employed in this study is developed by the Heritage Foundation [22]. It is a composite index of 12 indicators covering the four broad categories of rule of law (government integrity, property protection, judicial effectiveness), government size ( government spending, tax burden, fiscal health), regulatory efficiency ( business, labor, monetary freedom), and open markets( trade, investment, and financial freedom). Gropper, Lawson, and Thorne (2012) used the same specification of equation 2, and a similar specification with an interaction term between economic freedom index and GDP [11], suggesting the possibility that the effect of economic freedom on happiness could vary by GDP level (equation (3)). A similar approach is adopted in this study. Because of the low correlation between sleep and the economic freedom index, no interaction term is employed between the two variables.

$$
\text { Happiness }_{\mathrm{j}}=b_{0}+b_{1} \mathrm{Sleep}_{\mathrm{j}}+b_{2} \mathrm{GDP}_{\mathrm{j}}+b_{3} \text { Unemployment }_{\mathrm{j}} b_{4} \text { Environment }_{\mathrm{j}}
$$

where GDPj $\times$ Economicfreedom $j$ represents the interaction term between GDP and economic freedom. 


\section{RESULTS AND DISCUSSION}

\subsection{FIRST MODEL SPECIFICATION}

A summary of the variables statistics is shown in table 1 . The regression model results are shown in table 2 . The model and the variables are significant at the $5 \%$ level. The standardized beta coefficient which shows the change in one standard deviation of the dependent variable, given a change in one standard deviation of the independent variable shows similar coefficients (0.2) for sleep minutes, per capita GDP, and unemployment ( table 2(a)). This coefficient means that a change in one standard deviation of sleep minutes, per capita GDP or unemployment, results in a change in the happiness index by about $20 \%$ of its standard deviation. Meanwhile, the standardized beta coefficient of the environment performance index is higher, as it shows that an increase in the environment performance index by 1 standard deviation results in a change in the happiness index by $40 \%$ of its standard deviation. Examining unstandardized beta coefficients, an increase in sleep time by 10 minutes, results in an improvement in the happiness score by 0.1 points, noting that the average happiness score is 6.2 in the country sample. Increasing the per capita GDP by 10,000 International Dollars improves the happiness score by 0.1 points. Decreasing unemployment rate by $1 \%$, improves the happiness score by 0.05 points.

Table 1. Summary Statistics of the Study Variables

\begin{tabular}{|l|l|l|l|l|l|}
\hline Variable & $\mathrm{N}$ & Mean & Std. Dev. & Min & Max \\
\hline Happiness Score & 55 & 6.2 & 0.9 & 4.0 & 7.8 \\
\hline Sleep Duration in Minutes & 55 & 427.2 & 19.6 & 377.0 & 460.0 \\
\hline Environmental Performance Index & 55 & 66.7 & 11.5 & 30.6 & 87.5 \\
\hline $\begin{array}{l}\text { Per Capita GDP (PPP)-thousand } \\
\text { international dollars }\end{array}$ & 55 & 37.4 & 22.5 & 6.9 & 107.6 \\
\hline Index of Economic Freedom & 55 & 69.0 & 9.2 & 51.9 & 90.2 \\
\hline Unemployment Rate \% & 55 & 6.3 & 4.5 & 0.7 & 27.0 \\
\hline
\end{tabular}

Table 2. Ordinary Least Squares of Happiness Score- First Model Specification ( $\mathrm{N}=55)$

\begin{tabular}{|c|c|c|c|c|c|c|}
\hline \multirow[t]{2}{*}{ Variable } & \multicolumn{2}{|c|}{$\begin{array}{l}\text { All Independent } \\
\text { Variables } \\
\text { (a) }\end{array}$} & \multicolumn{2}{|c|}{$\begin{array}{c}\text { Dropping Per Capita } \\
\text { GDP } \\
\text { (b) }\end{array}$} & \multicolumn{2}{|c|}{$\begin{array}{c}\text { Dropping } \\
\text { Environmental } \\
\text { Performance Index } \\
\text { (c) }\end{array}$} \\
\hline & B & $\beta$ & B & $\beta$ & $\mathrm{B}$ & $\beta$ \\
\hline $\begin{array}{l}\text { Sleep Duration in } \\
\text { minutes }\end{array}$ & $0.01^{\star *}$ & 0.22 & $0.01^{* *}$ & 0.22 & $0.02^{\star * *}$ & 0.40 \\
\hline Unemployment Rate \% & $-0.05^{\star \star}$ & -0.22 & $-0.05^{\star *}$ & -0.27 & $-0.05^{\star *}$ & -0.22 \\
\hline $\begin{array}{l}\text { Environmental } \\
\text { Performance Index }\end{array}$ & $0.04^{* * *}$ & 0.48 & $0.05^{\star * *}$ & 0.60 & - & - \\
\hline $\begin{array}{l}\text { Per Capita GDP (PPP), } \\
\text { Int } \$ 1000\end{array}$ & $0.01^{\star *}$ & 0.22 & - & - & $0.02^{\star * *}$ & 0.45 \\
\hline Intercept & -0.78 & - & -1.21 & - & -2.29 & - \\
\hline $\mathrm{F}$ & $24.11^{* * *}$ & $29.17^{* * *}$ & $20.85^{\star * *}$ & & & \\
\hline Adjusted R-squared & 0.63 & 0.61 & 0.52 & & & \\
\hline
\end{tabular}

B: Beta Coefficient, b: Standardized Beta Coefficient

${ }^{* *}$ p-value $<5 \%$, ${ }^{* *}$ p-value $<1 \%$ 
Using the Breusch-Pagan / Cook-Weisberg test for heteroscedasticity [23], the null hypothesis of constant variance of residuals was not rejected at any of the conventional levels of significance (p-value=0.14) [23]. Also, the Ramsey test for omitted variables was employed to test the null hypothesis that there are no omitted variables [23] , and the null hypothesis was not rejected at any significance level ( $\mathrm{p}$-value $=0.9$ ).

To test for multicollinearity, the variance inflation factor is employed as a test for whether the variance of any of the independent variables or the overall model is inflated due to multicollinearity [23]. None of the variables show a value greater than 2.1, which indicates that the multicollinearity issue is not of high concern (the conventional threshold for indicating multicollinearity is above 10). However, the correlation between the estimated regression model coefficients test indicated weak to average correlation between the environmental performance index and each of sleep minutes and GDP per capita. While Troser (2019) suggests correlation between per capita GDP and sleep duration [15], the post estimation correlation matrix of coefficients showed weak correlation between the two variables that did not exceed -0.33 (noting that the sign of the post estimation correlation coefficients are opposite to the actual correlation between the variables since they indicate the degree to which the correlation affects the estimated coefficients; a coefficient of -0.33 indicates that the sleep coefficient is slightly underestimated due to this correlation). While the above should be noted for further examination in future studies, multicollinearity did not have a substantial impact on the model coefficients, which remained significant. Removing the environmental performance coefficient resulted in doubling the beta coefficients for each of GDP per capita and sleep hours, but unemployment was not affected as it did not correlate with environmental performance (table 2(b)). However, the adjusted R-squared was reduced from 63\% to 55\%. Removing the GDP variable (table 2(c)), the sleep duration coefficient did not change, but the environment coefficient increased from 0.47 to 0.6 , and the adjusted R-squared decreased slightly compared to the original specification from $63 \%$ to $61 \%$. This indicates that the environment performance coefficient captured most of the effect of the variability caused by differences in per capita GDP level. It can also be concluded that the sleep coefficient remained robust to different model specifications.

\subsection{SECOND MODEL SPECIFICATION}

The results are shown in table 3. Using equation (2), the regression and the variable coefficients are significant at the 5\% level, but the economic freedom index is only significant at the $8 \%$ level. Building on Gropper, Lawson and Thorne [11] and given the correlation between GDP and economic freedom, an interaction term is tested using equation (3). Under this specification, all the model variables are significant at the $1 \%$ level. The interaction term is negative which means that the effect of improvement in economic freedom increases at lower GDP levels. The standardized beta of sleep duration under this model specification is close to that of the first model specification (0.32 under equation (2) and 0.26 under equation (3) versus 0.22 under equation (1)). Similar to the first model specification, the values of standardized beta coefficients of sleep duration and per capita GDP are close to each other in equation 2. Under the second model specification, a 10 minute increase in sleep duration leads to an improvement in the happiness score by 0.12 to 0.15 points (compared to 0.1 points under equation 1 , and 0.2 points when the environmental performance index variable was dropped from that equation). It can be concluded that the relationship between sleep duration and happiness index proved to be significant with consistent estimates at different model specifications.

In both equations 2 and 3, using the Breusch-Pagan / Cook-Weisberg test for heteroscedasticity, the null hypothesis of constant variance of residuals was not rejected at any of the conventional levels of significance. Also, the Ramsey test for omitted variables was employed to test the null hypothesis that there are no omitted variables, and the null hypothesis was not rejected at any significance level ( $\mathrm{p}$-value=0.9). For equation 2 , the variance inflation factor did not detect an alarming level of 
multicollinearity, as none of the variables showed a value greater than 2 . However, the interaction factor was tested in equation 3 based on recommendations from previous literature [11].

Table 3. Ordinary Least Squares of Happiness Score- Second Model Specification $(\mathrm{N}=55)$

\begin{tabular}{|c|c|c|c|c|}
\hline Variable & $\begin{array}{l}\text { Equation } 2 \\
\text { (Without } \\
\text { Interaction } \\
\text { Term) }\end{array}$ & $\begin{array}{l}\text { Equation } 3 \\
\text { (Including } \\
\text { Interaction } \\
\text { Term) }\end{array}$ & & \\
\hline & B & $\beta$ & $\mathrm{B}$ & $\beta$ \\
\hline Sleep Duration in minutes & $0.015^{\star * *}$ & 0.33 & $0.012^{\star * *}$ & 0.26 \\
\hline $\begin{array}{l}\text { Per Capita GDP (PPP) in } \\
\$ 1000\end{array}$ & $0.015^{\star \star}$ & 0.35 & $0.132^{\star \star *}$ & 3.19 \\
\hline Economic Freedom Index & $0.025^{*}$ & 0.25 & $0.076^{* * *}$ & 0.76 \\
\hline $\begin{array}{l}\text { Per Capita GDP } \times \\
\text { Economic Freedom }\end{array}$ & - & - & $-.002^{\star * *}$ & -3.21 \\
\hline Intercept & -2.629 & - & -4.820 & - \\
\hline $\mathbf{F}$ & $19.82^{\star * *}$ & $23.83^{\star \star \star}$ & & \\
\hline Adjusted R-squared & 0.51 & 0.63 & & \\
\hline
\end{tabular}

B: Beta Coefficient, b: Standardized Beta Coefficient

${ }^{\star} \mathrm{p}$-value $<10 \%,{ }^{* *} \mathrm{p}$-value $<5 \%,{ }^{* *} \mathrm{p}$-value $<1 \%$

\section{CONCLUSIONS}

Sleep duration can explain some of the variation in the happiness score across countries. An increase in average sleep duration by 10 minutes results in an improvement in the happiness score by a range of 0.1 to 0.15 points, noting an average happiness score of 6.2 in the country sample. The relationship between sleep duration and happiness score was robust to alternative model specifications. Two alternative model specifications were used. The first included average sleep minutes per country, GDP (purchasing power parity), unemployment, and environmental performance index. The second model specification included average sleep minutes per country, GDP (purchasing power parity), and economic freedom index. Both model specifications met several robustness checks, showed overall significance and significant coefficients. There was little difference in the value of estimated coefficient of sleep in the alternative specifications.

This article's results are useful for drawing the attention of policy makers towards the importance of policies that address the problem of sleep inadequacy, and along with evidence from previous research that estimates the economic cost of inadequate sleep, could provide a justification for allocating more resources to such policies. Examples of policies which target sleep inadequacy include improving access to treatment services of sleep disorders, public awareness about the importance of adequate sleep and the effects of electronic media on sleep, and regulation of work hours and school start times [24]. The article also sheds light on the importance of directing more resources to research in the area of examining the relationship between happiness and sleep. It is recommended that Sleep Cycle collect data about happiness levels of its users, and the Gallup survey of happiness include questions about average sleep duration and sleep quality attributes in order to collect a more comprehensive cross-country dataset about sleep adequacy and its relationship with happiness. 


\section{REFERENCES}

[1] Hillman, D. et al. (2018). The economic cost of inadequate sleep, Sleep, 41(8): 1- 13, https://doi.org/10.1093/sleep/zsy083

[2] Hafner, M., et al. (2016). Why sleep matters - the economic costs of insufficient sleep: A crosscountry comparative analysis. Santa Monica, CA: RAND Corporation. https:/www.rand.org/pubs/ research_reports/RR1791.html.

[3] Shin, J. E., and Kim, J. K. (2018).: The Role How a Good Sleep Predicts Life Satisfaction of ZeroSum Beliefs About Happiness. Frontiers in psychology, 9, 1589. doi:10.3389/fpsyg.2018.01589.

[4] Piper, A.T. (2015). Sleep duration and life satisfaction. The German Socio-Economic Panel study. 745, Berlin: DIW.

[5] Baglioni, C, et al. (2011). Insomnia as a predictor of depression: a meta-analytic evaluation of longitudinal epidemiological studies. Journal of affective disorders, 135( 1-3): 10-9. doi: 10.1016/j. jad.2011.01.011.

[6] Dinges, D.F, et al. (1997). Cumulative sleepiness, mood disturbance, and psychomotor vigilance performance decrements during a week of sleep restricted to 4-5 hours per night. Sleep. 20(4):267-77.

[7] Easterlin, R A.(1974). Does Economic Growth Improve the Human Lot? Some Empirical Evidence. In David, P.A. and Reder, M.V(Eds), Nations and Households in Economic Growth: Essays in Honor of Moses Abramovitz (pp. 89-125). New York: Academic Press. Available at: https://carleton.ca/linr/ wp-content/uploads/15-Easterlin-1974-and-2010-1.pdf

[8] Easterlin, R. A. et al. (2011). The Happiness-Income Paradox Revisited. IZA Discussion Paper No. 5799.

[9] Stevenson, B. and Wolfers, J. (2008). Economic Growth and Subjective Well-Being: Reassessing the Easterlin Paradox. Brookings Papers on Economic Activity. Economic Studies Program, The Brookings Institution, 39(1 (Spring), 1-102.

[10] Deaton, A. (2008). Income, health, and well-being around the world:Evidence frovariablevariablem the Gallup World Poll. Journal of Economic Perspectives. 22:53-72.

[11] Gropper, D., R. Lawson and J. Thorne, Jr. 2011. Economic freedom and happiness. Cato Journal. 31: 237-255.

[12] Helliwell, J., Layard, R., and Sachs, J. (2019). World Happiness Report 2019, New York: Sustainable Development Solutions Network.

[13] Gorham, E., Lehman, C. and Kelly. J. (2019). Relationships of the Environmental Performance Index to Six Interrelated Variables in Nations Around the World. The Bulletin of the Ecological Society of America. 100(2):e01525. https://doi.org/10.1002/bes2.1525

[14] Majeed, M.T. and Mumtaz, S. (2017). Happiness and Environmental Degradation: A Global Analysis. Pakistan Journal of Commerce and Social Sciences. 11 (3), 753-772.

[15]Troser, J. (2019). Which Countries get the most sleep?. The Economist. https://www.1843magazine. com/data-graphic/what-the-numbers-say/which-countries-get-the-most-sleep

[16] Sleep Cycle (2014). New Zealand got the most sleep of all countries in November. https://www. sleepcycle.com/wp-content/uploads/2014/12/November-World-of-Sleep.pdf

[17] World Bank. (2019). World Development Indicators. Washington, D.C.: The World Bank (producer and distributor). http://data.worldbank.org/data-catalog/world-development-indicators [18] Wendling, Z. et al. (2018). 2018 Environmental Performance Index. New Haven, CT: Yale Center for Environmental Law and Policy. https://epi.yale.edu/

[19]World Justice Project. (2018). WJP Rule of Law Index 2017-2018. IBSN (online version): 9780-9882846-3-0. Washington, D.C. : World Justice Project. https://worldjusticeproject.org/sites/ default/files/documents/WJP-ROLI-2018-June-Online-Edition_0.pdf

[20] Transparency International (2019). Corruption Perceptions Index 2018. https://www. transparency.org/cpi2018

[21] Lang, J. (2012). The Most Influential Factors in Determining the Happiness of Nations. Major 
Themes in Economics. 14 (5). https://scholarworks.uni.edu/mtie/vol14/iss1/5

[22] Miller, T., Kim, A.B., and Roberts, J.M. (2019). 2019 Index of Economic Freedom. 25th Anniversary Edition. Washington, D.C. :The Heritage Foundation. https://www.heritage.org/index/ pdf/2019/book/index_2019.pdf

[23] STATA(2019). Basic Reference Manual-Post Estimation Tools for Regress. https://www.statapress.com/manuals/r_regresspost.pdf

[24] Barnes, C.M and Drake, C.L.(2015). Prioritizing Sleep Health: Public Health Policy Recommendations. Perspectives on Psychological Science. 10(6): 733-737.

\section{APPENDIX}

Sleep Duration and Happiness Score of the countries included in the Sample

Figure A.1 Sleep Duration and Happiness Score by Country

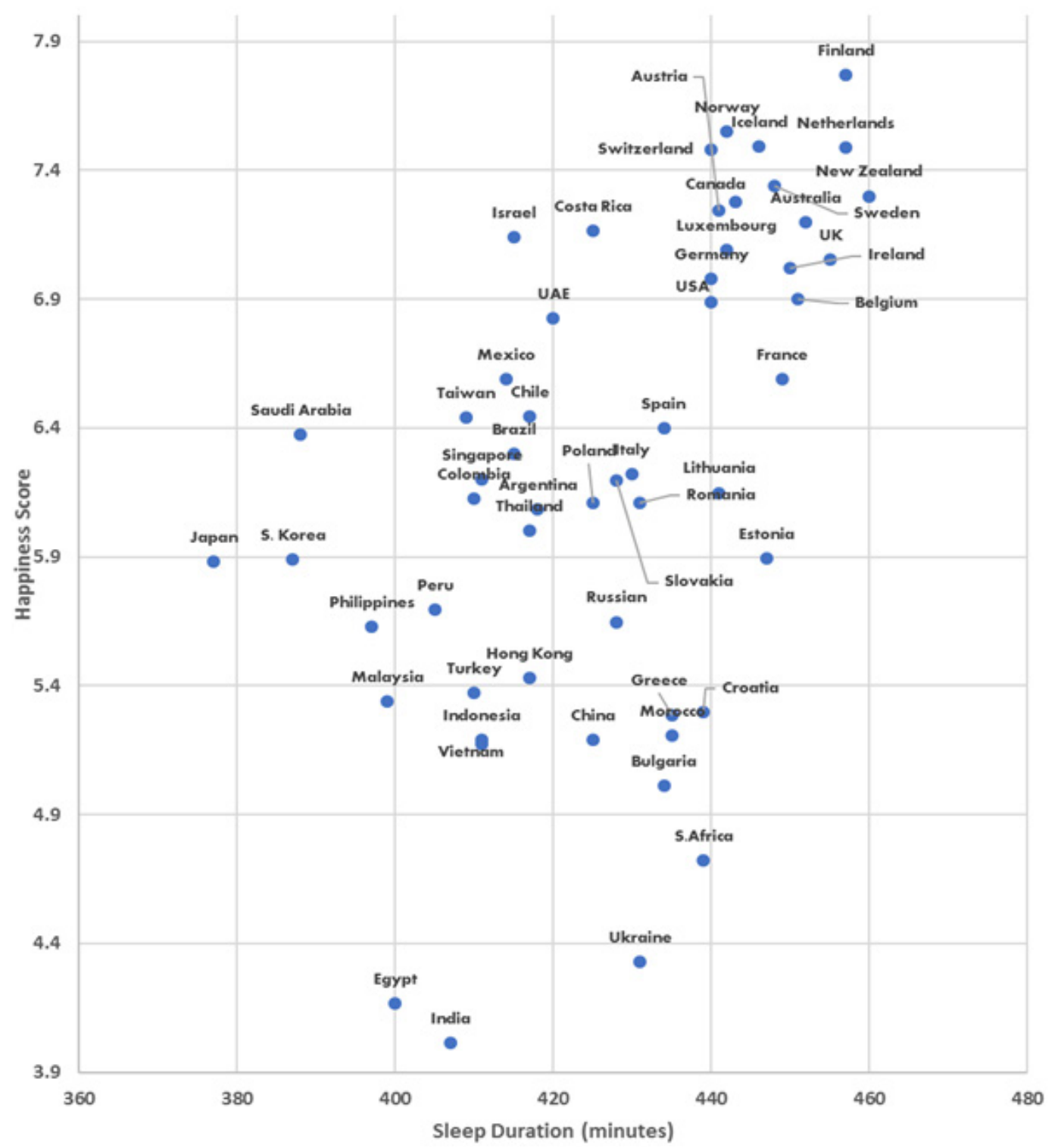

Source: Sleep data from [15 ] and Happiness Score from [12]. 